\title{
P2X7 purinoceptors contribute to the death of Schwann cells transplanted into the spinal cord
}

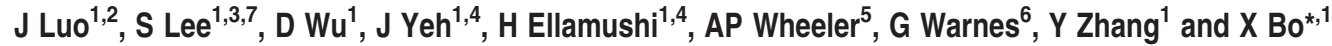

The potential to use Schwann cells (SCs) in neural repair for patients suffering from neurotrauma and neurodegenerative diseases is well recognized. However, significant cell death after transplantation hinders the clinical translation of SC-based therapies. Various factors may contribute to the death of transplanted cells. It is known that prolonged activation of P2X7 purinoceptors (P2X7R) can lead to death of certain types of cells. In this study, we show that rat SCs express P2X7R and exposure of cultured SCs to high concentrations of ATP (3-5 mM) or a P2X7R agonist, 2'(3')-0-(4-benzoylbenzoyl)ATP (BzATP) induced significant cell death rapidly. High concentrations of ATP and BzATP increased ethidium uptake by SCs, indicating increased membrane permeability to large molecules, a typical feature of prolonged P2X7R activation. SC death, as well as ethidium uptake, induced by ATP was blocked by an irreversible P2X7R antagonist oxidized ATP (oxATP) or a reversible P2X7R antagonist A438079. oxATP also significantly inhibits the increase of intracellular free calcium induced by minimolar ATP concentrations. Furthermore, ATP did not cause death of SCs isolated from P2X7R-knockout mice. All these results suggest that P2X7R is responsible for ATP-induced SC death in vitro. When rat SCs were treated with oxATP before transplantation into uninjured rat spinal cord, 35\% more SCs survived than untreated SCs 1 week after transplantation. Moreover, 58\% more SCs isolated from P2X7R-knockout mice survived after being transplanted into rat spinal cord than SCs from wild-type mice. This further confirms that P2X7R is involved in the death of transplanted SCs. These results indicate that targeting P2X7R on SCs could be a potential strategy to improve the survival of transplanted cells. As many other types of cells, including neural stem cells, also express P2X7R, deactivating P2X7R may improve the survival of other types of transplanted cells.

Cell Death and Disease (2013) 4, e829; doi:10.1038/cddis.2013.343; published online 3 October 2013

Subject Category: Neuroscience

Schwann cells (SCs) have been considered as a potential source for cell-based therapies for neurotrauma and some neurodegenerative diseases, as this type of peripheral glial cell can be obtained from the patients and used for autologous transplantation. SCs can be expanded efficiently in vitro with improved culture formula to make the cell-based therapy clinically feasible. The first case of clinical trial of SC transplantation into injured spinal cord has been carried out by the Miami Project to Cure Paralysis. SCs transplanted into the central nervous system (CNS) can promote axon regeneration and remyelination and improve functional recovery in animal models of spinal cord injury. ${ }^{1}$ However, early and extensive cell death occurring after transplantation is a common phenomenon and a significant obstacle that hinders the success of cell-based therapies. ${ }^{2,3}$ Therefore, a crucial issue of cell-based therapies is how to improve cell survival after transplantation. Many factors may contribute to the death of transplanted cells, such as inflammation, immune response, oxidative stress and lack of growth factors. Although various approaches have been investigated to tackle those factors, ${ }^{4}$ the survival of transplanted cells is still far from being satisfactory, indicating that additional unidentified factors are involved. One such factor could be ATP released at the transplantation site. Tissue damage and inflammation lead to the release of various cytokines and mediators as well as high levels of extracellular ATP. 5,6 The transplantation procedure will inevitably cause a certain degree of tissue damage and instant ATP release from the injured cells. Moreover, the space occupied by the transplanted cells will press the surrounding host tissues, which may trigger by mechanical deformation further release of ATP from astrocytes. ${ }^{7}$ Inflammation and ischemia can also trigger ATP release from microglia ${ }^{8}$ and oligodendrocytes. ${ }^{9}$ Such local increases in extracellular ATP level may activate P2X7

\footnotetext{
${ }^{1}$ Centre for Neuroscience and Trauma, Blizard Institute, Queen Mary University of London, London E1 2AT, UK; ${ }^{2}$ Department of Physiology, Tongji Medical College, Huazhong University of Science and Technology, Wuhan 430030, China; ${ }^{3}$ College of Korean Medicine, Semyung University, Jechon 390-711, South Korea; ${ }^{4}$ Department of Neurosurgery, London E1 2AT, UK; ${ }^{5}$ Blizard Advanced Light Microscopy Core Facility, London E1 2AT, UK and ${ }^{6}$ Flow Cytometry Core Facility, Blizard Institute, Barts and the London School of Medicine and Dentistry, Queen Mary University of London, 4 Newark Street, London E1 2AT, UK

${ }^{*}$ Corresponding author: X Bo, Centre for Neuroscience and Trauma, Blizard Institute, Queen Mary University of London, 4 Newark Street, London E1 2AT, UK. Tel: + 4420 78822294; Fax: + 4420 78822180; E-mail: x.bo@qmul.ac.uk

${ }^{7}$ This author made equal contribution.

Keywords: purinoceptor; ATP receptor; Schwann cell; cell death; cell transplantation; spinal cord injury

Abbreviations: SC, Schwann cell; oxATP, oxidized ATP; BzATP, 2'(3')-O-(4-benzoylbenzoyl)ATP; P2X7R, P2X7 purinoceptor; CNS, central nervous system; IL-1 $\beta$, interleukin-1 $\beta$; BBG, Brilliant Blue G; DMEM, Dulbecco's modified Eagle's medium; $\left[\mathrm{Ca}^{2+}\right]_{\text {, }}$, ree intracellular calcium

Received 28.3.13; revised 17.7.13; accepted 05.8.13; Edited by A Verkhratsky
} 
purinoceptors (P2X7R) on the transplanted cells and induce cell death.

Activation of P2X7R by ATP leads to rapid opening of cation channels. ${ }^{10-12}$ Prolonged exposure to high concentrations of ATP $(>100 \mu \mathrm{M})$ makes homomeric P2X7R permeable to large cations. Pores formed on the membrane allow molecules up to $900 \mathrm{Da}$ (such as YO-PRO-1 and ethidium) to pass through the cell membrane and lead to cell death. ${ }^{13}$ P2X7R-mediated cell death has been reported in several types of cells, such as macrophages ${ }^{14}$ and dendritic cells. ${ }^{15}$ In the nervous system, functional P2X7R is expressed by microglia, astrocytes, ${ }^{16}$ oligodendrocytes, ${ }^{17}$ and some neurons in the brain and spinal cord. ${ }^{18}$ Prolonged stimulation of P2X7R is reported to cause death of microglia, ${ }^{19}$ photocells, ${ }^{20}$ and neural progenitor cells. ${ }^{21}$ P2X7R has been identified on mouse SCs by electrophysiology and immunohistochemistry. ${ }^{22}$ In the current study, we investigated whether ATP could induce SC death in vitro and explored the role of P2X7R in ATP-induced SC death. Furthermore, we examined whether P2X7R in SCs contributed to SC death after transplantation into the spinal cord.

\section{Results}

SCs express P2X7R. Cultured rat SCs were doubleimmunostained for P2X7R and the SC marker S100. P2X7R immunoreactivity was distributed all over the cells, whereas S100 immunoreactivity was much stronger in the nuclei (Figure 1a). PCR using rat SC cDNAs and a pair of P2X7R-specific primers produced a DNA band of the same size as that using P2X7R cDNA as template, demonstrating that the P2X7R mRNA is expressed in SCs (Figure 1b). Immunostaining of rat sciatic nerves showed the colocalization of P2X7R and S100 immunoreactivity in SCs (Figure 1c). The P2X7R immunoreactivity was stronger in SchmidtLanterman incisures, the tubular cytoplasm structures inside the myelin sheath. P2X7R immunoreactivity was absent or very weak on axons labeled with N52 antibody for neurofilament 200 (Figure 1c). A similar pattern of immunostaining of $\mathrm{P} 2 \mathrm{X} 7 \mathrm{R}$ and $\mathrm{S} 100$ was seen in the sciatic nerve of wild-type C57BI/6J mice (Figure 1d). However, no immunoreactivity for P2X7R was detected in the sciatic nerve from the P2X7Rknockout mice from GlaxoSmithKline (Figure 1d). This result confirms the specificity of the P2X7R antibody.
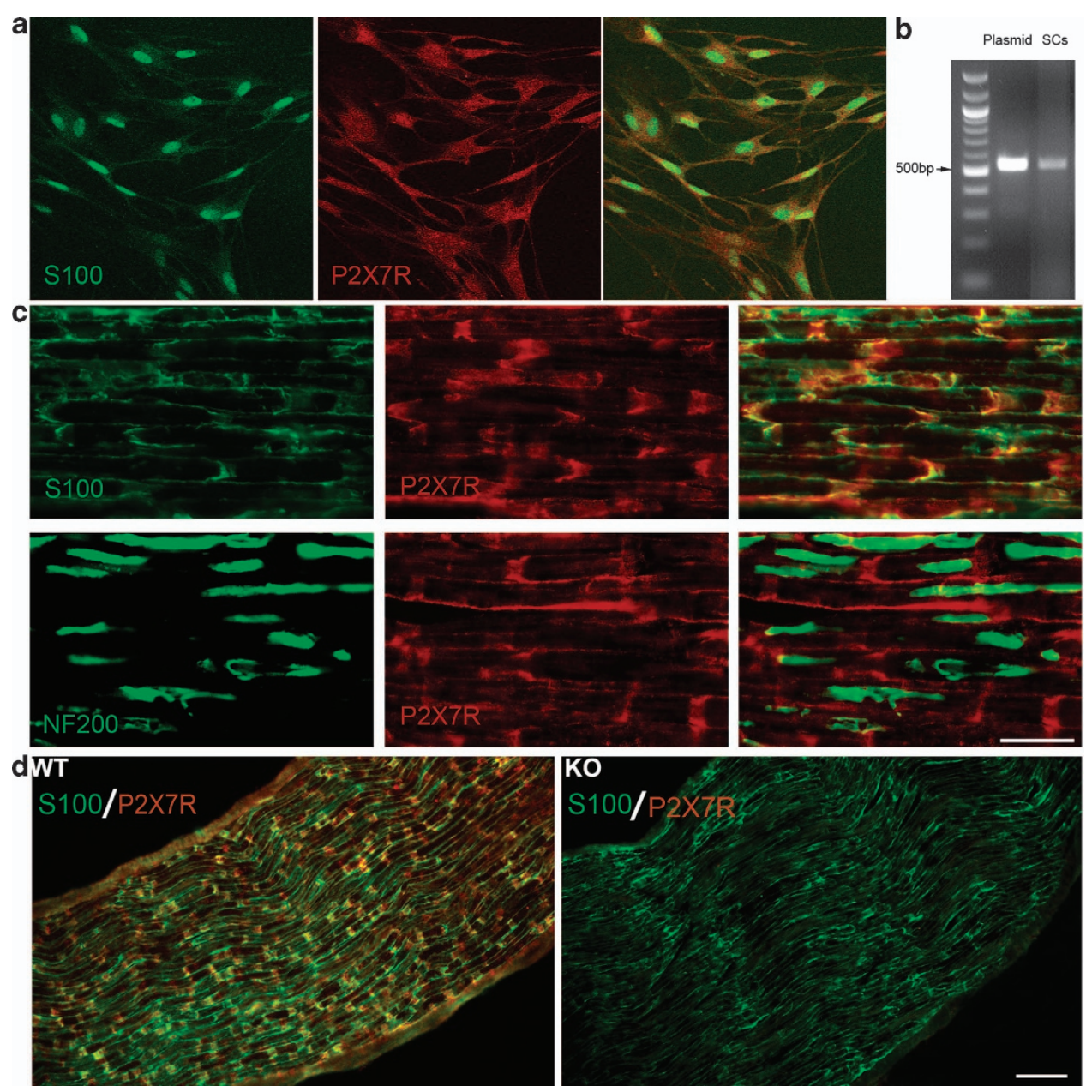

Figure 1 P2X7R is expressed in isolated SCs and sciatic nerves from rat and mouse. (a) Photomicrograph of cultured rat SCs double-immunostained for the SC marker S100 and P2X7R. (b) Detection of P2X7R mRNA in cultured rat SCs using PCR. (c) Photomicrographs of longitudinal sections through the rat sciatic nerve doubleimmunostained for S100 and P2X7R or NF200 and P2X7R. Scale bar, $50 \mu \mathrm{m}$. (d) Photomicrographs of longitudinal sections through the sciatic nerves from C57BI/6J wild-type (WT) and P2X7R-knockout (KO) mice double-immunostained for S100 and P2X7R. Scale bar, $100 \mu \mathrm{m}$ 
ATP induces the death of cultured SCs dose-dependently. During an experiment looking for potential factors that might induce SC death, we exposed SCs to various concentrations of ATP. No obvious morphological change occurred to SCs exposed to ATP concentrations up to $1 \mathrm{mM}$ (Figure 2a); however, SCs exposed to ATP concentrations higher than $2 \mathrm{mM}$ underwent significant morphological changes within 10-15 min; the higher the concentration, the quicker the changes occurred. Cell processes started to withdraw and cells gradually rounded up (Figure $2 \mathrm{a}$ ). Most of the SCs detached from the culture dishes after exposure to $5 \mathrm{mM}$ ATP for $1 \mathrm{~h}$. Cells were then dissociated, labeled with Annexin V Apoptosis Assay kit and subjected to flow cytometry to measure cell viability. No significant SC death occurred after exposure to 1 or $2 \mathrm{mM}$ ATP (Figure 2c). However, at $3 \mathrm{mM}$ cell death became significant and 4 and $5 \mathrm{mM}$ ATP induced even more profound cell death (Figures $2 b$ and $c)$.

As only high ATP concentrations induced SC death, P2X7R is implicated to be the receptor responsible for $\mathrm{SC}$ death. We further tested 2'(3')-O-(4-benzoylbenzoyl)ATP (BzATP), the most potent, although not highly specific, agonist for P2X7R. Cells exposed to $200 \mu \mathrm{M}$ BzATP started to withdraw their processes within $15 \mathrm{~min}$. By $30 \mathrm{~min}$, nearly all the cells rounded and many detached. Cell viability assay showed that significantly lower percentage of cells was alive after exposure to BzATP than the control group (Figure $2 \mathrm{c}$ ). These results indicate that P2X7R may mediate the SC death induced by ATP and BzATP.

P2X7R antagonists prevent ATP- or BzATP-induced SC death. To further confirm that $P 2 X 7 R$ is responsible for ATP-induced SC death, we tested whether blocking P2X7R could prevent ATP-induced SC death. Oxidized ATP (oxATP), an irreversible and slow action P2X7R antagonist, $^{23}$ was applied to the cultured SCs to a final concentration of $350 \mu \mathrm{M}$ for $2 \mathrm{~h}$. oxATP-treated and -untreated cells were then exposed to various concentrations of ATP or $200 \mu \mathrm{M}$ BzATP for $1 \mathrm{~h}$. During this period, cells treated with oxATP did not show observable morphological changes. SCs were then processed for cell viability assay. Pretreatment with oxATP did not cause significant cell death (Figure 2c); however, oxATP pretreatment completely prevented cell death induced by various concentrations of ATP and $200 \mu \mathrm{M}$ BzATP (Figure 2c).
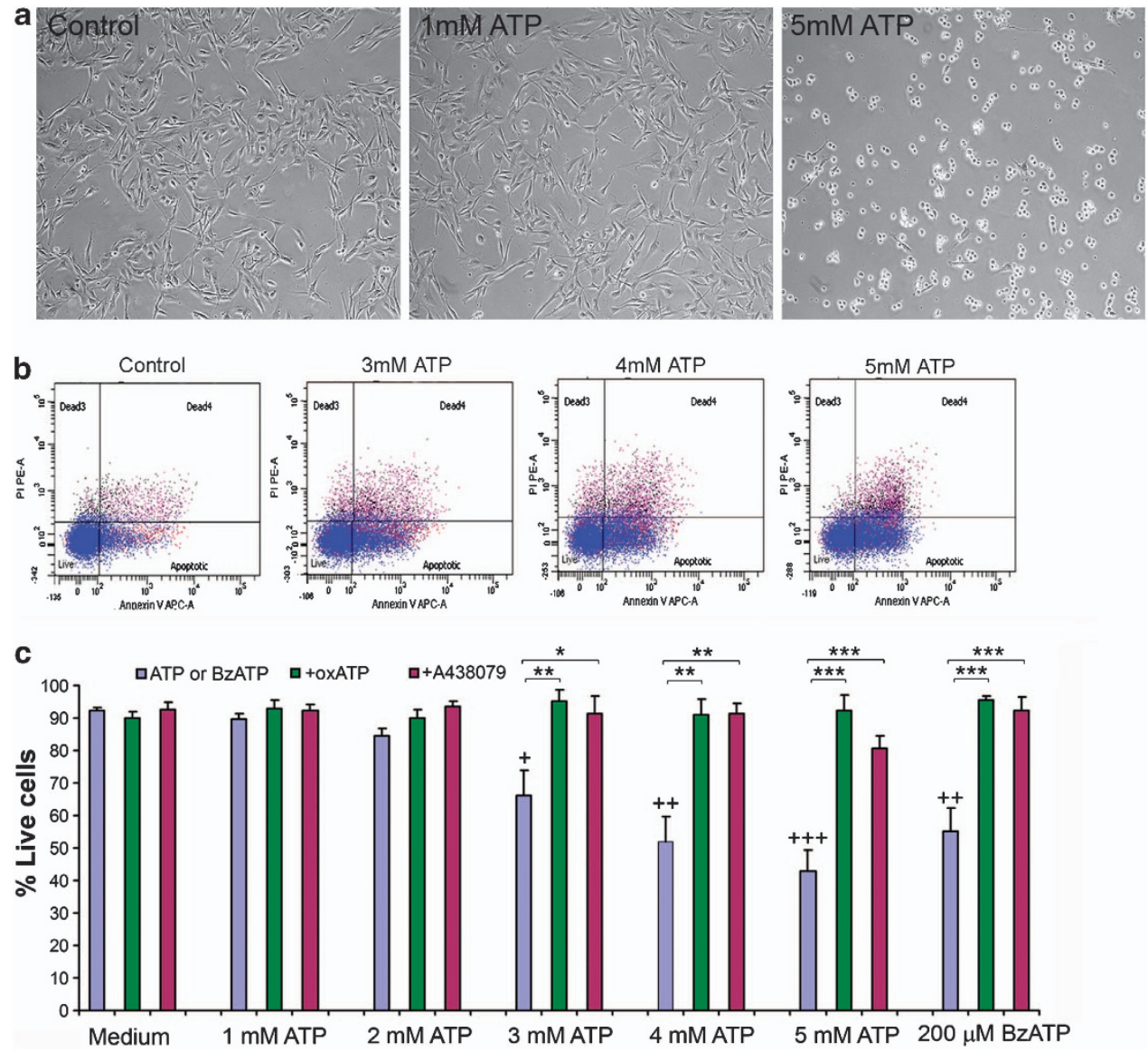

Figure 2 ATP induces SC death dose-dependently in vitro. (a) Phase contrast images showing SCs in culture with or without exposure to ATP for 30 min. (b) Flow cytometry cell viability assay showing the proportions of live cells after exposure to $3,4,5 \mathrm{mM}$ ATP for $1 \mathrm{~h}$. (c) The percentage of live SCs after being exposed to increasing concentrations of ATP or BzATP $(200 \mu \mathrm{M})$ with or without oxATP $(350 \mu \mathrm{M})$ or A438079 $(100 \mu \mathrm{M}){ }^{+} P<0.05,{ }^{++} P<0.01,{ }^{+++} P<0.001$ (compared with the group without ATP); ${ }^{\star} P<0.05,{ }^{* *} P<0.01,{ }^{* \star *} P<0.001$ (compared between the corresponding groups with or without one of the antagonists), single factor AVNOA, $n=3-7$ 
oxATP was reported to attenuate pro-inflammatory signaling by acting through $\mathrm{P} 2$ receptor-independent mechanisms. ${ }^{24}$ Therefore, there exists certain possibility that the prevention of ATP-induced cell death by oxATP may not be solely through the blockade of P2X7R. We then tested a reversible specific P2X7R antagonist, A438079. ${ }^{25}$ At $100 \mu \mathrm{M}, \mathrm{A} 438079$ itself did not affect the morphology and viability of SCs, but it also completely blocked the ATP- and BzATP-induced cell death (Figure 2c). The results demonstrate that both oxATP and A438079 can protect SCs from ATP-induced cell death, indicating that $\mathrm{P} 2 \mathrm{X} 7 \mathrm{R}$ is responsible for SC death.

\section{ATP does not induce death of SCs from P2X7R-knockout} mice. Experiment on SCs from P2X7R-knockout mice further supports that P2X7R is responsible for ATP-induced $\mathrm{SC}$ death. After exposure to $5 \mathrm{mM}$ ATP for $1 \mathrm{~h}$, no morphological change and significant cell death were detected in SCs dissociated from P2X7R-knockout mice (C57Bl/6J), whereas most of the SCs from the wild-type mice of the same strain were dead (Figure 7a). Compared with rat SCs, ATP-induced death is more profound in SCs from the wild-type mice.

P2X7R antagonists block ATP- and BzATP-induced ethidium uptake into SCs. Cell death induced by high concentrations of ATP is attributed to the prolonged activation of P2X7R, which leads to pore formation on cell membranes. ${ }^{12,13}$ To test whether ATP can also induce pore formation in SCs, SCs were exposed to various concentrations of ATP in the presence of $10 \mu \mathrm{M}$ ethidium bromide. Using time-lapse confocal microscopy, it was shown that a gradual increase in ethidium uptake into SCs occurred at ATP concentrations above $1 \mathrm{mM}$ (Figure 3c). Under an epifluorescence microscope, we also observed that ethidium uptake occurred at ATP concentrations above $1 \mathrm{mM}$ (Figures $3 a$ and b). By comparing the corresponding bright-field and fluorescence images of the same microscopic field taken at 20 min after exposure to ATP, it is evident that the extent of ethidium uptake is correlated with the morphological changes of SCs (Figure 3a). Quantification of ethidium fluorescence intensities in SCs 20 min after the exposure to ATP shows that ethidium uptake is concentration-dependent (Figure $3 b$ ). After pretreatment of SCs with $350 \mu \mathrm{M}$ oxATP for $2 \mathrm{~h}$ or $100 \mu \mathrm{M}$ A438079 for $20 \mathrm{~min}$, ATP at all tested concentrations did not induce ethidium uptake (Figure $3 b$ ), indicating the blockade of P2X7R prevents the pore formation on SCs.

We also noticed that high concentrations of ATP did not induce morphological change and ethidium uptake in a few contaminated fibroblasts (indicated by green arrows in Figure $3 a$ ), indicating that those fibroblasts are resistant to ATP-induced pore formation and cell death. Immunostaining of the SC culture with an anti-P2X7R antibody showed that P2X7R immunoreactivity was absent in those fibroblasts (unpublished observation).
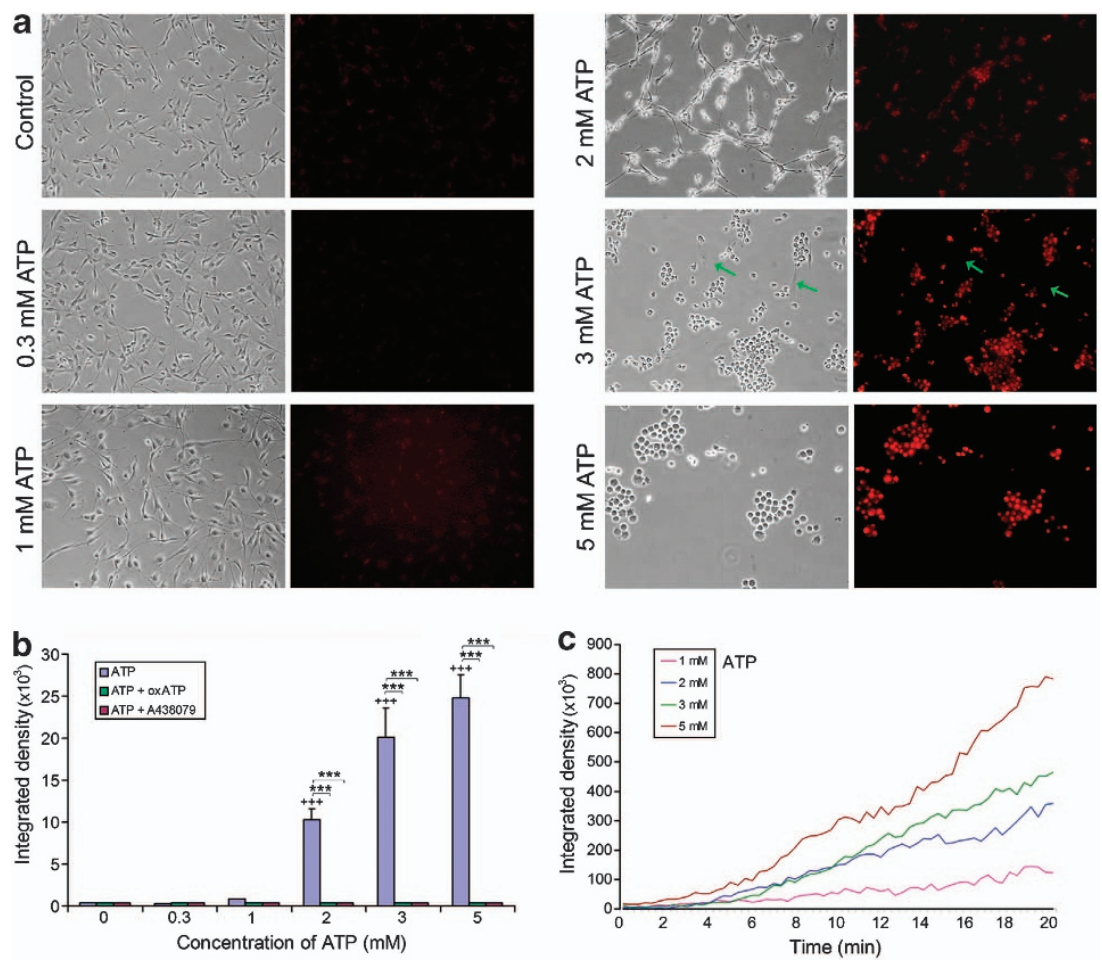

Figure 3 ATP induces ethidium uptake by SCs. (a) Photomicrographs showing the morphological changes of SCs (phase contrast images) and ethidium fluorescence in SCs $20 \mathrm{~min}$ after exposure to various concentrations of ATP. Green arrows in the two photomicrographs for $3 \mathrm{mM}$ ATP point to two fibroblasts. (b) Quantification of ethidium fluorescence intensities in SCs 20 min after exposure to various concentrations of ATP with or without oxATP $(350 \mu \mathrm{M})$ or A438079 $(100 \mu \mathrm{M})$ treatment. ${ }^{+++} P<0.001$ (compared with the group without ATP); ${ }^{* *} P<0.001$ (compared between the corresponding groups with and without one of the antagonists), single factor AVNOA, $n=3$. (c) Representative time course of ethidium uptake by SCs after exposure to different concentrations of ATP over 20 min 
P2X7R antagonists inhibit ATP- and BzATP-induced increase in free intracellular $\mathbf{C a}^{2+}$ in SCs. ATP and other P2 purinoceptor agonists have been reported to evoke the increase of free intracellular $\mathrm{Ca}^{2+}\left(\left[\mathrm{Ca}^{2+}\right]_{\mathrm{i}}\right)$ in dissociated or myelinating SCs. ${ }^{26,27}$ We tested a wider range of ATP concentrations for a longer time $(15 \mathrm{~min})$ on SCs with and without pretreatment with oxATP. From 1 to $300 \mu \mathrm{M}$ ATP evoked a rapid $\left[\mathrm{Ca}^{2+}\right]_{i}$ increase and the transient rise gradually declined to and maintained at the baseline level (Figure 4b). However, at 1, 3 and $5 \mathrm{mM}$ ATP, after the peak phase $\left[\mathrm{Ca}^{2+}\right]_{i}$ level gradually elevated again over the recording period. Quantification of the intensity and duration of the peak $\left[\mathrm{Ca}^{2+}\right]_{\mathrm{i}}$ rise by combining the Fluo-4 fluorescence intensities during the first $100 \mathrm{~s}$ after ATP application shows that the $\left[\mathrm{Ca}^{2+}\right]_{i}$ increase is generally concentration-dependent (Figure 4d). However, the peak phase of $\left[\mathrm{Ca}^{2+}\right]_{i}$ rise at $5 \mathrm{mM}$ ATP was lower than those at 1 and $3 \mathrm{mM}$, a phenomenon that we are unable to explain at the moment. Pretreatment with oxATP did not affect the peak phase of $\left[\mathrm{Ca}^{2+}\right]_{i}$ rise evoked by ATP concentrations lower than $300 \mu \mathrm{M}$ but reduced the peak phases for 1 and $3 \mathrm{mM}$ ATP (Figures 4c and d). Another obvious difference between the two groups is that oxATP pretreatment prevented the gradual $\left[\mathrm{Ca}^{2+}\right]_{i}$ rise after the peak response at 1,3 and $5 \mathrm{mM}$ ATP (Figure 4c). Therefore, it is postulated that the gradual $\left[\mathrm{Ca}^{2+}\right]_{i}$ rise after the peak
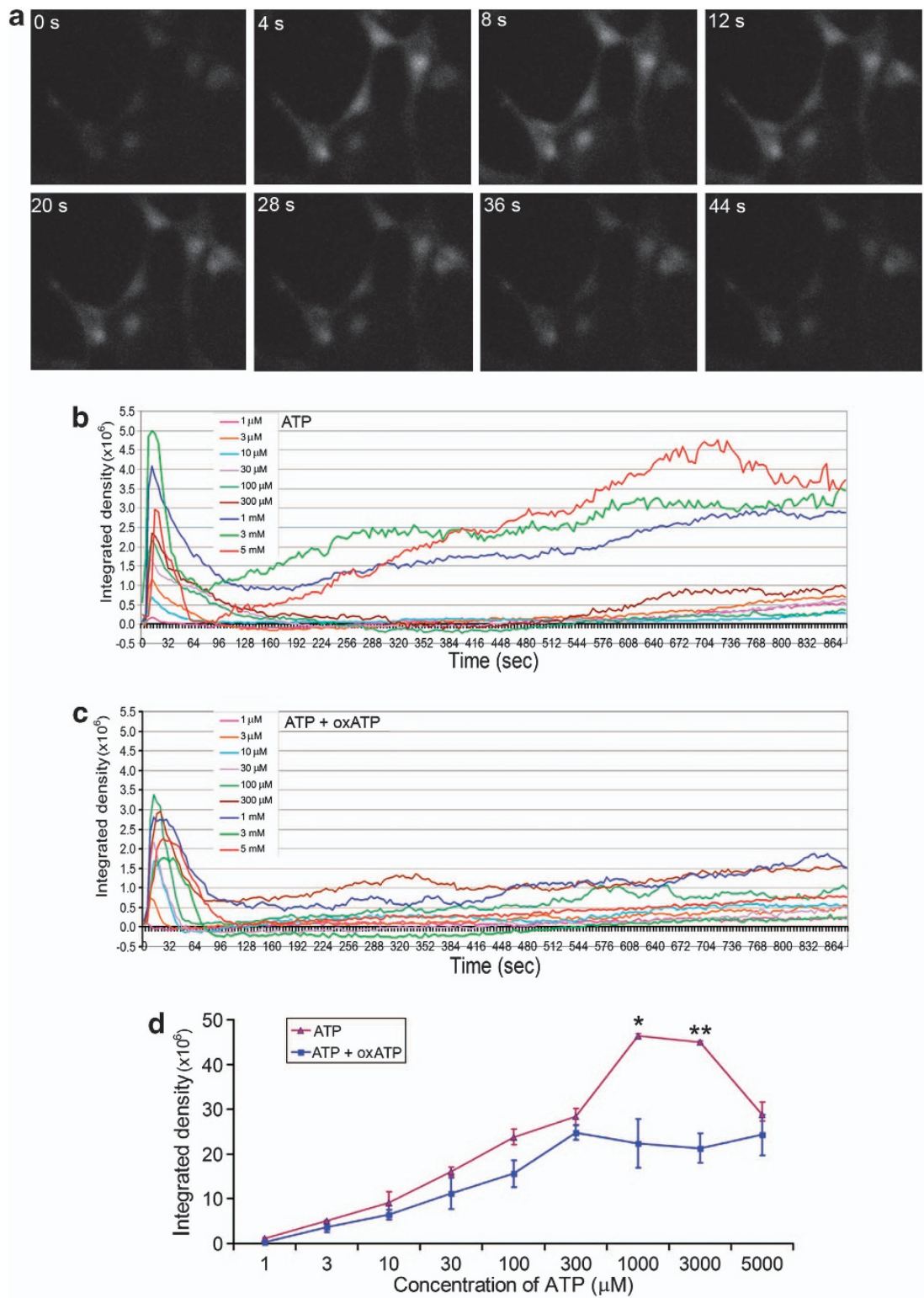

Figure 4 ATP increases $\left[\mathrm{Ca}^{2+}\right]_{\mathrm{i}}$ level in SCs. (a) Sequential images of Fluo-4 fluorescence captured by a time-lapse microscope over a period of $44 \mathrm{~s}$ in SCs pretreated with $350 \mu \mathrm{M}$ oxATP and then exposed to $30 \mu \mathrm{M}$ ATP. (b) Representative time course of $\left[\mathrm{Ca}^{2+}\right]_{i}$ levels indicated by Fluo- 4 fluorescence intensities in SCs after exposure to different concentrations of ATP. (c) Representative time course of $\left[\mathrm{Ca}^{2+}\right]_{\mathrm{i}}$ levels in SCs pretreated with oxATP $(350 \mu \mathrm{M})$ and then exposed to different concentrations of ATP. (d) Quantification of Fluo-4 fluorescence intensities in SCs in the first $100 \mathrm{~s}$ (peak phase) after exposure to different concentrations of ATP with or without oxATP treatment. ${ }^{\star} P<0.05,{ }^{*} P<0.01$ (compared between groups exposed to the same concentration of ATP with and without oxATP), single factor ANOVA, $n=3$ 
may be due to the $\mathrm{Ca}^{2+}$ influx through the pores formed on the membrane.

BzATP was also able to evoke $\left[\mathrm{Ca}^{2+}\right]_{i}$ rise in SCs (Figure $5 \mathrm{a}$ ), and quantification of the intensity and duration of the peak phase of $\left[\mathrm{Ca}^{2+}\right]_{i}$ rise in the first $180 \mathrm{~s}$ after BzATP application shows that the $\left[\mathrm{Ca}^{2+}\right]_{i}$ increase is generally concentration-dependent (Figures $5 \mathrm{a}$ and $\mathrm{c}$ ). BzATP at $30 \mu \mathrm{M}$ evoked a small $\left[\mathrm{Ca}^{2+}\right]_{\mathrm{i}}$ rise, whereas $100 \mu \mathrm{M}$ evoked a much bigger $\left[\mathrm{Ca}^{2+}\right]_{\mathrm{i}}$ rise that lasted longer than minimolar ATP-evoked $\left[\mathrm{Ca}^{2+}\right]_{i}$ rise. After the peak response, $\left[\mathrm{Ca}^{2+}\right]_{i}$ remained at the baseline level. Three hundred micromolar BzATP evoked a slightly bigger peak $\left[\mathrm{Ca}^{2+}\right]_{i}$ rise than $100 \mu \mathrm{M}$; however, $\left[\mathrm{Ca}^{2+}\right]_{i}$ gradually elevated after the peak, similar to that seen with minimolar ATP concentrations. A438079 at $100 \mu \mathrm{M}$ significantly reduced BzATP-induced peak $\left[\mathrm{Ca}^{2+}\right]_{i}$ rise and abolished the gradual $\left[\mathrm{Ca}^{2+}\right]_{i}$ rise induced by $300 \mu \mathrm{M}$ BzATP (Figures $5 \mathrm{~b}$ and c), indicating that the $\left[\mathrm{Ca}^{2+}\right]_{i}$ rise induced by BzATP is mainly mediated by P2X7R.
Pretreatment of SCs with oxATP improves their survival after transplantation. To test whether blockade of P2X7R can improve the survival of transplanted SCs, we exploited the property of irreversible blockade of P2X7R by oxATP. After the irreversible blockade of P2X7R, new P2X7Rs need to be synthesized and transported to the cell membrane before they become susceptible to ATP-induced death again. First, we studied the time window for SCs to remain resistant to ATP-induced cell death after oxATP treatment. SCs were incubated with $350 \mu \mathrm{M}$ oxATP for $2 \mathrm{~h}$ and oxATP was then removed. At 2-6h after oxATP removal, SCs were exposed to $5 \mathrm{mM}$ ATP. It was found that ATP-induced withdrawal of cellular processes started to appear at $4 \mathrm{~h}$ after oxATP removal and became more obvious at $6 \mathrm{~h}$ (data not shown). This $4 \mathrm{~h}$ window may be long enough to offer a certain degree of protection against ATP-induced SC death after transplantation, as ATP release occurs instantly at the site of transplantation and may last for several hours. $^{28}$
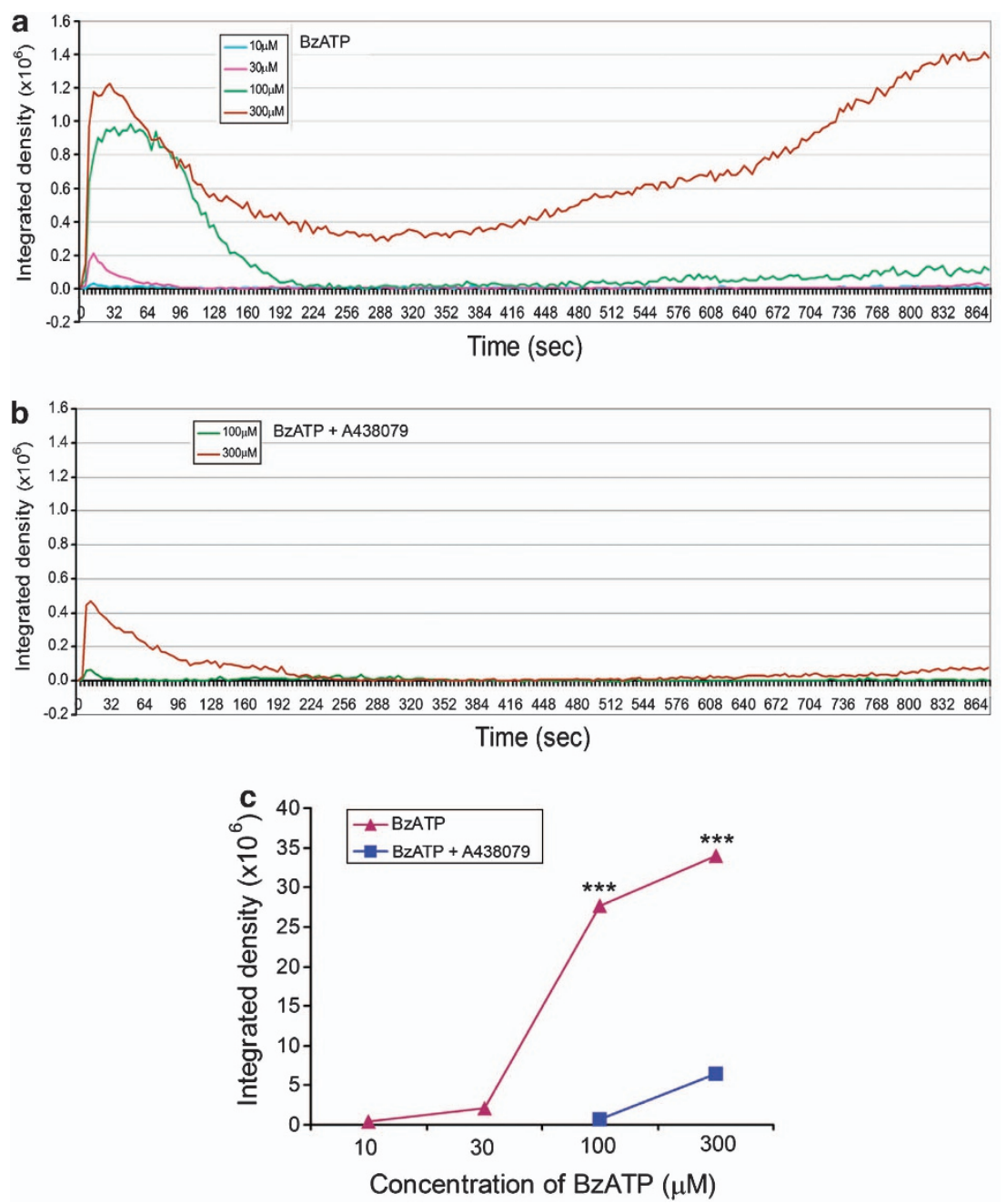

Figure 5 A438079 inhibits BzATP-induced $\left[\mathrm{Ca}^{2+}\right]_{\text {i }}$ increase in SCs. (a) Representative time course of $\left[\mathrm{Ca}^{2+}\right]_{\mathrm{i}}$ levels indicated by Fluo-4 fluorescence intensities in SCs after exposure to different concentrations of BzATP. (b) Representative time course of $\left[\mathrm{Ca}^{2+}\right]_{i}$ levels in SCs exposed to different concentrations of BzATP with A438079 $(100 \mu \mathrm{M})$. (c) Quantification of Fluo-4 fluorescence intensities in SCs in the first $180 \mathrm{~s}$ (peak phase) after exposure to different concentrations of BzATP with or without A438079. ${ }^{* * *} P<0.001$ (compared between groups exposed to the same concentration of BzATP with and without A438079), single factor ANOVA, $n=3$ 
Five days before transplantation, SCs were transduced with a GFP-expressing lentivirus for easy identification and quantification. One dish of cells was treated with $350 \mu \mathrm{M}$ oxATP for $2 \mathrm{~h}$, whereas another dish of untreated cells was used as control. Both groups of cells were harvested simultaneously and 100000 cells were transplanted into either side of dorsal columns at the thoracic eight level of the spinal cord of adult rats ( $n=4$, Figure $6 a)$. One week later, animals were killed and the areas occupied by GFP ${ }^{+}$SCs in the spinal cord sections were measured using ImageJ (NIH, Bethesda, MD, USA). Transplanted SCs mainly remained at the injection site, with some cells spreading into the host tissue (Figure 6b). Quantification data show that $34.9 \pm 7.2 \%$ more oxATP-treated SCs survived than the untreated SCs after transplantation (Figure 6c, $P<0.01$, paired Student's $t$-test), indicating that blocking P2X7R in SCs can improve their survival after transplantation.

P2X7R knockout enhances the survival of transplanted SCs. To test whether SCs deficient of P2X7R can survive better after transplantation, we isolated SCs from C57BI/6J wild-type and P2X7R-knockout mice, and then transduced them with GFP-expressing adenovirus, as mouse SCs are not susceptible to lentiviral transduction. The same numbers of cells (100000) from wild-type or P2X7R-knockout mice were transplanted into either side of dorsal columns at the thoracic eight level of the spinal cord of adult rats $(n=5)$. Animals were injected with ciclosporin daily after surgery to suppress immune rejections. One week later, animals were killed and the areas occupied by GFP ${ }^{+}$SCs in the spinal cord sections (Figure $7 \mathrm{~b}$ ) were measured using ImageJ. It was found that $54.8 \pm 8.8 \%$ more SCs from P2X7R-knockout mice survived compared with those from wild-type mice (Figure 7c, $P<0.01$, paired Student's $t$-test), which indicates that P2X7R knockout can promote the survival of transplanted SCs.

\section{Discussion}

An important discovery in the current study is that high concentrations of ATP can induce SC death in vitro. The evidence provided indicates that the P2X7R is the
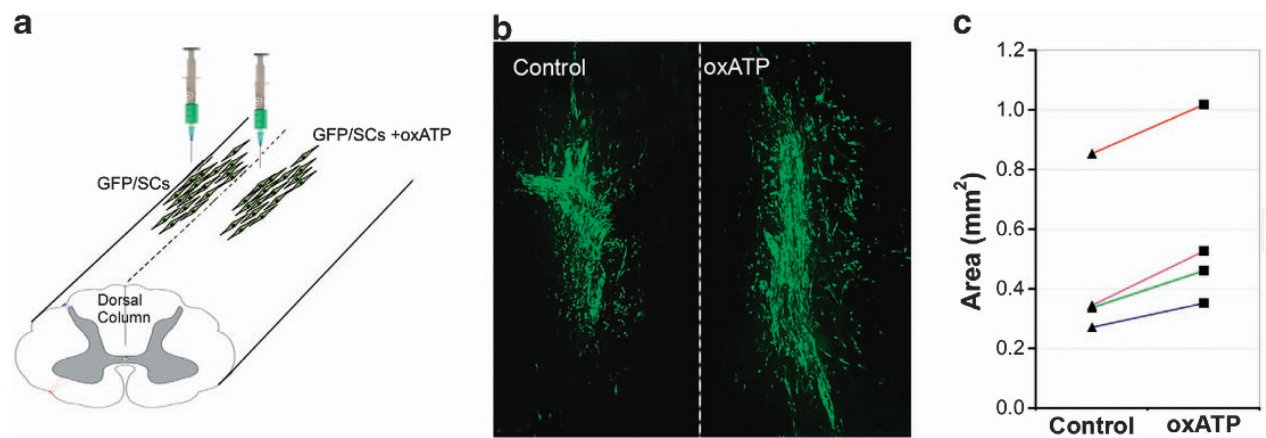

Figure 6 Blockade of P2X7R on SCs increases their survival after transplantation. (a) Diagram illustrating the transplantation of GFP-expressing SCs (GFP/SCs) with or without oxATP treatment into either side of the dorsal column of rat T8 spinal cord. (b) Photomicrographs showing GFP/SCs transplanted into the spinal cord. Dashed line indicates midline of spinal cord. (c) Quantification of the areas occupied by GFP/SCs with or without oxATP pretreatment in the spinal cords of four rats (data from the same animal are linked by colored lines)
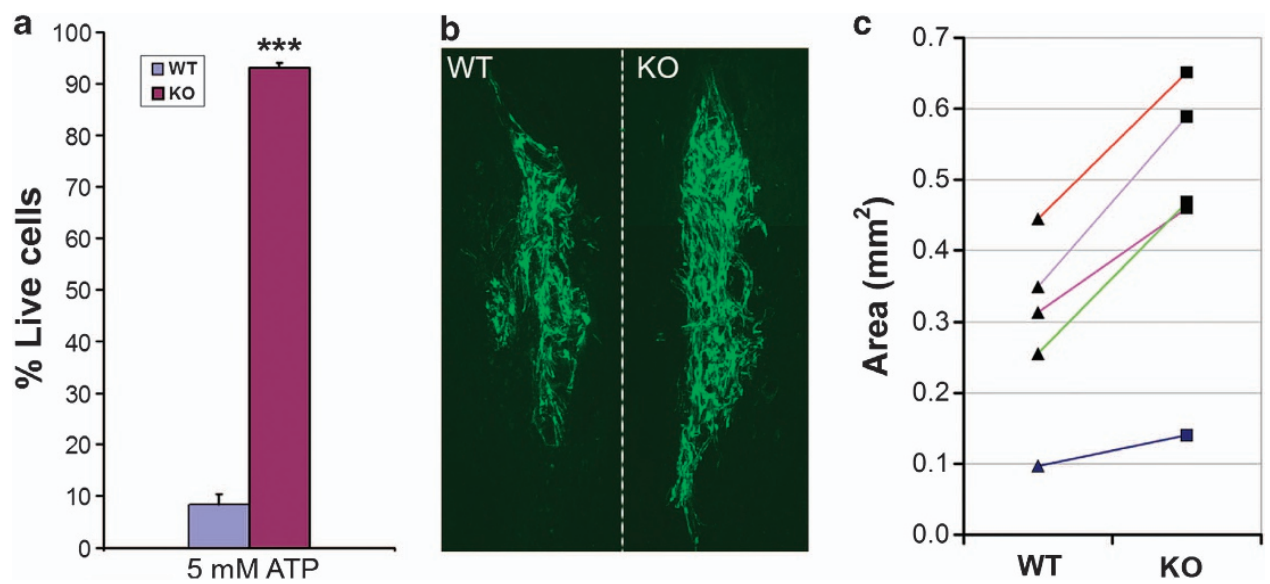

Figure 7 P2X7R-deficient SCs are resistant to ATP-induced cell death and survive better after transplantation. (a) Flow cytometry apoptosis assay showing that $5 \mathrm{mM}$ ATP induced significant death of SCs from wild-type (WT) mice, whereas SCs from P2X7R-knockout (KO) mice did not show obvious cell death. ${ }^{* * *} P<0.001$, Student's t-test, $n=4$. (b) Photomicrograph showing the surviving GFP-expressing mouse SCs from WT or P2X7R KO mouse 1 week after transplantation into rat spinal cords. (c) Quantification of the areas occupied by GFP/SCs from WT or P2X7R KO mice transplanted into the spinal cords of five rats (data from the same animal are linked by colored lines) 
purinoceptor subtype that mediates SC death. The first line of evidence is that only high concentrations of ATP can induce significant SC death. It is well-known that prolonged activation of P2X7R by ATP in minimolar concentrations leads to the formation of large transmembrane pores resulting in the movement of solutes across membranes and cell death. ATPinduced SC death is concentration-dependent; however, cell death occurs in a rather narrow range of concentrations, which has also been observed in ATP-induced death of dendritic cells and neural progenitor cells. ${ }^{15,21}$ The steep concentration-response curve may be due to that the extent of pore formation reaches a critical level at a certain concentration of ATP and the leakage of intracellular contents becomes so severe in some cells that they enter the death path irreversibly. This is supported by our observation that ethidium uptake became evident at $2 \mathrm{mM}$ ATP, so did the morphological changes of SCs; however, no significant cell death was detected using flow cytometry at this concentration. Cell death becomes statistically significant at $3 \mathrm{mM} \mathrm{ATP}$.

The significant SC death induced by BzATP may provide another line of evidence to support that $P 2 X 7 R$ is responsible to SC death. However, it should be noted that BzATP may act as a partial agonist for other $\mathrm{P} 2 \mathrm{X}$ and $\mathrm{P} 2 \mathrm{Y}$ receptor subtypes. ${ }^{29}$ Both ATP- and BzATP-induced cell death was completely blocked by P2X7R antagonists oxATP and A438079. These two antagonists also completely blocked the ethidium uptake induced by minimolar ATP concentrations, further supporting that pore formation on SC membrane may lead to cell death.

ATP at concentrations from 1 to $5 \mathrm{mM}$ can evoke $\left[\mathrm{Ca}^{2+}\right]_{\mathrm{i}}$ increase in SCs. OxATP only significantly reduced the peak $\left[\mathrm{Ca}^{2+}\right]_{i}$ increase induced by 1 and $3 \mathrm{mM}$ ATP, whereas it had no significant effect on lower concentration of ATP. oxATP also abolished the gradual $\left[\mathrm{Ca}^{2+}\right]_{i}$ rise after the peak response that was only obvious at minimolar ATP concentrations. The results further implicate that oxATP can efficiently block the P2X7R in SCs.

The last, also the most convincing, evidence to support that P2X7R is responsible for ATP-induced SC death is from the cell viability assay of SCs from P2X7R-knockout mice, which shows that disruption of P2X7R gene expression abolished the ATP-induced SC death. All the evidence above indicates that $P 2 X 7 R$ is the receptor subtype that is responsible for ATP-induced cell death.

We speculate that ATP may contribute to the death of the transplanted SCs in the spinal cord. One crucial question is whether ATP released during the transplantation procedure will reach concentrations high enough to induce $\mathrm{SC}$ death. It is known that ATP concentrations in cells are in the range of $1-10 \mathrm{mM}^{30}$ Upon cell breakage after injury, intracellular ATP will be released and the local concentration of ATP could reach the minimolar level. Sustained high-level ATP release at the site of a spinal cord injury was reported to last for $6 \mathrm{~h}^{28}$ In cell transplantation procedures, even when carried out very carefully to minimize damage to the host tissue, a certain degree of injury is inevitable. Furthermore, ATP released by injury will attract microglia and macrophages to the transplantation site and these cells may release more ATP. ${ }^{8}$ We did observe the accumulation of Iba-1 (a microglia and macrophage marker) positive cells around the SC implants 1 day after transplantations (data not presented). Therefore, it is highly possible that ATP released at the transplantation site may reach the minimolar level and induce the death of transplanted SCs.

By using the irreversible antagonist oxATP to block P2X7R on SCs before transplantation, we were able to significantly increase the survival of SCs in the spinal cord. Furthermore, P2X7R knockout in SCs showed an even larger increase in SC survival after transplantation. Taken together, these data indicate that ATP and P2X7R are involved in the cell death after transplantation. However, to improve the survival of transplanted SCs by pretreatment with oxATP may not be an ideal approach, as oxATP has other targets such as ATPbinding enzymes ${ }^{31}$ and may be cytotoxic. ${ }^{32}$ At $350 \mu \mathrm{M}$, oxATP itself does not affect SC viability. Another reason is that, although the blockade by oxATP is irreversible, newly synthesized P2X7R will make SCs sensitive to ATP again $4 \mathrm{~h}$ after oxATP removal. This may partially explain why more P2X7R knockout SCs survived than oxATP-treated SCs in vivo. However, it should be noted that mouse SCs were more susceptible to ATP-induced cell death in vitro, which may be attributed to species difference. Other approaches that specifically target P2X7R and have longer lasting effects need to be developed. One potential approach is to use small interfering RNA (siRNA) to knockdown P2X7R in SCs before transplantation.

P2X7R has been reported to participate in the processing and release of cytokines, such as interleukin-1 $\beta$ (IL-1 $\beta)$, and in the initiation of cell death via both apoptotic and necrotic pathways. ${ }^{33}$ In the CNS, P2X7R has been implicated in many pathological processes, including neuroinflammation. ${ }^{16,34,35}$ P2X7R-mediated release of inflammatory factors at the injury site may also contribute to the death of transplanted cells. In the normal rodent brain, P2X7R expression in astrocytes is generally quite low, but quickly upregulated in response to brain injury or pro-inflammatory stimulation in cell culture conditions. ${ }^{36,37}$ In astrocytes, P2X7R activation can potentiate pro-inflammatory signaling, as it enhances IL-1 $\beta$ induced activation of nuclear factor $-\kappa \mathrm{B}$ and activator protein $1 .^{38,39}$ Such processes may lead to more inflammatory factor release via the activation of P2X7R. It is likely that more cell death will occur after cells are transplanted into the lesioned spinal cord. It was reported that intravenous administration of Brilliant Blue G (BBG), a selective P2X7R antagonist, significantly reduced spinal cord damage. ${ }^{40} \mathrm{BBG}$ treatment also directly reduced local activation of astrocytes and microglia and neutrophil infiltration. We predict that administration of a P2X7R antagonist to rats before transplantation may also enhance the survival of transplanted SCs. If such treatment is effective, further enhancement of SC survival may be achieved by combining the administration of P2X7R antagonist with P2X7R knockdown in SCs.

In conclusion, the results from the present study indicate that blocking P2X7R on SCs promotes their survival after transplantation, which may lead to improved neural repair. As many other types of cells, such as neural stem cells and pancreatic beta cells, also express P2X7R, our finding that P2X7R is involved in the death of transplanted cells may have a significant impact in the cell therapy field. 


\section{Materials and Methods}

SC culture and viral vector transduction. SCs were isolated from the sciatic nerves and brachial plexus of Wistar rats or C57BI/6J mice of postnatal day 2 as described previously. ${ }^{41,42}$ Cells were then maintained in Dulbecco's modified Eagle's medium (DMEM) containing $10 \%$ fetal bovine serum (FBS), $25 \mathrm{ng} / \mathrm{ml}$ $\beta$-heregulin (R\&D Systems Europe Ltd, Abingdon, UK), $2 \mu \mathrm{M}$ forskolin (Sigma-Aldrich, Poole, UK), $25 \mathrm{ng} / \mathrm{ml}$ fibroblast growth factor (PeproTech EC Ltd, London, UK) and $5 \mu \mathrm{g} / \mathrm{ml}$ insulin (Sigma-Aldrich). The purity of all primary SC cultures was evaluated by immunostaining for the SC markers p75 neurotrophin receptor $\left(\mathrm{p} 75^{\mathrm{NTR}}\right.$ ) and $\mathrm{S100}$. Highly purified cultures (>95\% SCs), up to three passages, were used in all experiments. For easy identification after transplantation, cultured rat SCs were transduced with a GFP-expressing third generation lentiviral vector made in our $\mathrm{lab}^{42,43}$ at a $\mathrm{MOI}$ of 10 and the transduction efficiency was about $95 \%$. Mouse SCs were transduced with GFP-expressing adenoviral vector made in our lab at a $\mathrm{MOI}$ of 10 and the transduction efficiency was about $98 \%$.

The P2X7R KO mice (homozygotes) were gifts from GlaxoSmithKline (Harlow, UK). Mice carrying a targeted null mutation of the $\mathrm{P} 2 \mathrm{X} 7$ gene were generated by inserting LacZ gene into Exon 1 of P2X7 gene to disrupt the P2X7 gene. ${ }^{44}$ Germline chimaeras were crossed with $\mathrm{C} 57 \mathrm{~B} / / 6 \mathrm{~J}$ females to generate heterozygotes, and a further six backcrosses onto the C57B//6J strain were performed before producing homozygotes for study.

Immunohistochemistry. Rat SCs and $10 \mu \mathrm{m}$ thick cryostat sections of the sciatic nerves from rat, wild-type and P2X7R KO mice were fixed with $4 \%$ paraformaldehyde and blocked in $10 \%$ normal donkey serum in PBS. The cells or tissue sections were incubated with a polyclonal antibody for P2X7R (1:70, Alomone, Jerusalem, Israel) and a monoclonal antibody for $S 100$ (1:2000, Sigma-Aldrich). Primary antibodies were diluted in 10\% normal donkey serum containing $0.2 \%$ Triton $X-100$ plus $1 \%$ bovine serum albumin in PBS. Secondary antibodies applied were donkey anti-mouse IgG-FITC $(1: 400$, Jackson ImmunoResearch Laboratories Inc., West Grove, PA, USA) and donkey anti-rabbit IgG-TRITC (1:400, Jackson ImmunoResearch Laboratories Inc.).

PCR. Cellular RNAs were extracted from SCs using TRIzol Reagent (Invitrogen, Life Technologies, Paisley, UK) and reverse transcribed using random hexanucleotide primers and SuperScript III Reverse Transcriptase (Invitrogen). cDNAs obtained were used for amplifying P2X7R cDNA with 30 PCR cycles. Aliquots of PCR products were electrophoresed in a $2 \%$ agarose gel. A plasmid containing P2X7R cDNA was used as a positive control.

Cell viability assays. SCs were cultured in $35 \mathrm{~mm}$ dishes to $65-70 \%$ confluence when experiments were performed. ATP solutions were prepared in PBS and adjusted to $\mathrm{pH}$ 7.2. After exposure to various concentrations of ATP and/or other compounds, cells were dissociated after trypsin treatment. Trypsinized SCs were centrifuged at $180 \times g$ for $10 \mathrm{~min}$ and cell viability was measured using an Annexin Apoptosis Assay kit (BD Biosciences, Oxford, UK). SCs were resuspended in $400 \mu \mathrm{l}$ Annexin V binding buffer and incubated with $2 \mu \mathrm{l}$ Annexin V-FITC at room temperature for $15 \mathrm{~min}$, then $5 \mu \mathrm{g} / \mathrm{ml}$ (final concentration) viability dye propidium iodide was added. The samples were subjected to flow cytometry.

Ethidium uptake. SCs were cultured in 24-well plates (Nunc). Ethidium uptake was monitored by stimulating SCs in culture medium with various concentrations of ATP in the presence of $10 \mu \mathrm{M}$ ethidium bromide for $20 \mathrm{~min}$. Using an inverted fluorescence microscope (Nikon Eclipse TE-2000E) cells were photographed with a $670 \mathrm{~nm}$ filter from three randomly chosen fields of view with fixed exposure time for all micrographs. For quantification of ethidium uptake, integrated densities of ethidium fluorescence in 20 randomly chosen cells from each micrograph were measured using ImageJ. The experiments were repeated using three different batches of cells.

To determine the time course of ethidium uptake after exposure of ATP, SCs in 24-well plates were placed on the stage of a spinning disk confocal microscope (Andor Technology plc, Belfast, UK) fitted with an environmental chamber (maintained at $37^{\circ} \mathrm{C}$ ). Ethidium bromide was added to the well to a final concentration of $10 \mu \mathrm{M}$. Cells were visualized using a Nikon $\times 10$ objective (0.3NA). Ethidium was excited at $561 \mathrm{~nm}$ laser and emitted fluorescence was filtered with a 580-620 nm bandpass filter. Images were captured on an iXon 885 EM CCD camera using IQ software (Andor Technology plc) over a period of $20 \mathrm{~min}$ at $20 \mathrm{~s}$ intervals. Two images were captured before the application of ATP to establish the baseline of ethidium fluorescence. Image J was used to quantify the ethidium uptake after exposure to ATP, and integrated densities of ethidium fluorescence in 10 randomly chosen cells in each captured image were measured and averaged. The experiments were repeated three times using different batches of cells.

Calcium imaging. SCs were cultured in 24-well plates and loaded with Fluo-4 Direct (Invitrogen) for $20 \mathrm{~min}$ at $37^{\circ} \mathrm{C}$. Cells were visualized with the same confocal microscope described above. The Fluo-4 was excited using a $488 \mathrm{~nm}$ laser and emitted fluorescence was filtered with a $505-530 \mathrm{~nm}$ bandpass filter. Time-lapse images were captured over a period of $15 \mathrm{~min}$ at $4 \mathrm{~s}$ intervals. Five images were captured as baseline before ATP or BzATP was applied to the well.

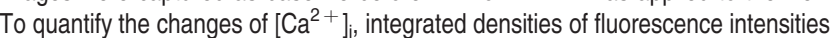
in 10 randomly chosen cells in each captured image were measured and averaged using ImageJ. The integrated densities of fluorescence from the same cells before the application of ATP were subtracted from all the measurements after the application of ATP. The experiments were repeated three times using different batches of SCs.

Cell transplantation. All animal work was performed in accordance with the Animals (Scientific Procedures) Act 1986 of the UK and covered by project and personal licenses issued by the Home Office. The protocol was approved by the Animal Ethical Review Committee of Queen Mary University of London. All efforts were made to minimize animal use and suffering. Adult female Wistar rats (200-250 g) were anesthetized with isoflurane, and GFP-expressing SCs (100000 in $1 \mu \mathrm{l}$ DMEM) were injected into either side of the dorsal column at the eighth thoracic segment of the spinal cord with a 33 gauge metal needle at a speed of $200 \mathrm{nl} / \mathrm{min} .{ }^{42}$ For rats receiving mouse SC transplants, ciclosporin was injected intraperitoneally $(10 \mathrm{mg} / \mathrm{kg}$, daily) till the animals were killed. As cell death mainly occurs in the first week after transplantation, the rats in the study were maintained for 1 week before killing. Rats were perfused with $4 \%$ paraformaldehyde and the spinal cord segments containing the transplants were removed and sectioned at $15 \mu \mathrm{m}$ thickness with a cryostat.

To quantify the cell survival in vivo, the areas occupied by transplanted rat or mouse SCs (visualized by GFP fluorescence) were measured in consecutive parasagittal sections of spinal cord $(45 \mu \mathrm{m}$ apart) with ImageJ. Statistical significance was determined using paired Student's t-test.

\section{Conflict of Interest}

The authors declare no conflict of interest.

Acknowledgements. We are very grateful to GlaxoSmithKline UK for providing the P2X7R KO mice. We thank JV Priestley, G Burnstock, and G Knight for critical reading of the manuscript. This work was supported by a Nathalie Rose Barr PhD Studentship from International Spinal Research Trust (NRB094) (to $Y Z$ and $X B$ ) and a Wellcome Trust grant (084688/Z/08/Z) to $X B$ and $Y Z)$. $Y Z$ was supported by a grant from Medtronic UK (to JY and HE). SL was supported by studentship from Semyung University (to XB and JY).

1. Fortun J, Hill CE, Bunge MB. Combinatorial strategies with Schwann cell transplantation to improve repair of the injured spinal cord. Neurosci Lett 2009; 456: 124-132.

2. Hill CE, Moon LD, Wood PM, Bunge MB. Labeled Schwann cell transplantation: cell loss, host Schwann cell replacement, and strategies to enhance survival. Glia 2006; 53: 338-343

3. Pearse DD, Sanchez AR, Pereira FC, Andrade CM, Puzis R, Pressman $Y$ et al. Transplantation of Schwann cells and/or olfactory ensheathing glia into the contused spinal cord: Survival, migration, axon association, and functional recovery. Glia 2007; 55: 976-1000.

4. Haider $\mathrm{H}$, Ashraf M. Strategies to promote donor cell survival: combining preconditioning approach with stem cell transplantation. J Mol Cell Cardiol 2008; 45: 554-566.

5. Fields RD, Burnstock G. Purinergic signalling in neuron-glia interactions. Nat Rev Neurosci 2006; 7: 423-436.

6. Khakh BS, North RA. P2X receptors as cell-surface ATP sensors in health and disease. Nature 2006; 442: 527-532.

7. Newman EA. Propagation of intercellular calcium waves in retinal astrocytes and Muller cells. J Neurosci 2001; 21: 2215-2223.

8. Dou Y, Wu HJ, Li HQ, Qin S, Wang YE, Li J et al. Microglial migration mediated by ATPinduced ATP release from lysosomes. Cell Res 2012; 22: 1022-1033.

9. Domercq M, Perez-Samartin A, Aparicio D, Alberdi E, Pampliega O, Matute C. P2X7 receptors mediate ischemic damage to oligodendrocytes. Glia 2010; 58: 730-740. 
10. Virginio C, MacKenzie A, North RA, Surprenant A. Kinetics of cell lysis, dye uptake and permeability changes in cells expressing the rat P2X7 receptor. J Physiol 1999; 519: 335-346.

11. North RA. Molecular physiology of P2X receptors. Physiol Rev 2002; 82: 1013-1067.

12. Volonte C, Apolloni S, Skaper SD, Burnstock G. P2X7 receptors: channels, pores and more. CNS Neurol Disord Drug Targets 2012; 11: 705-721.

13. Surprenant A, Rassendren F, Kawashima E, North RA, Buell G. The cytolytic $P 2 Z$ receptor for extracellular ATP identified as a P2X receptor (P2X7). Science 1996; 272: 735-738.

14. Falzoni S, Munerati M, Ferrari D, Spisani S, Moretti S, Di Virgilio F. The purinergic P2Z receptor of human macrophage cells. Characterization and possible physiological role. J Clin Invest 1995; 95: 1207-1216.

15. Coutinho-Silva R, Persechini PM, Bisaggio RD, Perfettini JL, Neto AC, Kanellopoulos JM et al. P2Z/P2X7 receptor-dependent apoptosis of dendritic cells. Am J Physiol 1999; 276: C1139-C1147.

16. Sperlagh B, Vizi ES, Wirkner K, Illes P. P2X7 receptors in the nervous system. Prog Neurobiol 2006; 78: 327-346.

17. Matute C. P2X7 receptors in oligodendrocytes: a novel target for neuroprotection. $\mathrm{Mol}$ Neurobiol 2008; 38: 123-128.

18. Deuchars SA, Atkinson L, Brooke RE, Musa H, Milligan CJ, Batten TF et al. Neuronal P2X7 receptors are targeted to presynaptic terminals in the central and peripheral nervous systems. J Neurosci 2001; 21: 7143-7152.

19. Ferrari D, Chiozzi P, Falzoni S, Dal Susino M, Collo G, Buell G et al. ATP-mediated cytotoxicity in microglial cells. Neuropharmacology 1997; 36: 1295-1301.

20. Notomi S, Hisatomi T, Kanemaru T, Takeda A, Ikeda Y, Enaida H et al. Critical involvement of extracellular ATP acting on P2RX7 purinergic receptors in photoreceptor cell death. Am J Pathol 2011; 179: 2798-2809.

21. Delarasse C, Gonnord P, Galante M, Auger R, Daniel H, Motta I et al. Neural progenitor cell death is induced by extracellular ATP via ligation of P2X7 receptor. J Neurochem 2009; 109: 846-857.

22. Colomar A, Amedee T. ATP stimulation of $P 2 X(7)$ receptors activates three different ionic conductances on cultured mouse Schwann cells. Eur J Neurosci 2001; 14: 927-936.

23. Di Virgilio F. Novel data point to a broader mechanism of action of oxidized ATP: the P2X7 receptor is not the only target. $\mathrm{Br} J$ Pharmacol 2003; 140: 441-443.

24. Beigi RD, Kertesy SB, Aquilina G, Dubyak GR. Oxidized ATP (OATP) attenuates proinflammatory signaling via $\mathrm{P} 2$ receptor-independent mechanisms. $\mathrm{Br} \mathrm{J}$ Pharmacol 2003; 140: 507-519.

25. Nelson DW, Gregg RJ, Kort ME, Perez-Medrano A, Voight EA, Wang Y et al. Structureactivity relationship studies on a series of novel, substituted 1-benzyl-5-phenyltetrazole P2X7 antagonists. J Med Chem 2006; 49: 3659-3666.

26. Lyons SA, Morell P, McCarthy KD. Schwann cells exhibit P2Y purinergic receptors that regulate intracellular calcium and are up-regulated by cyclic AMP analogues. J Neurochem 1994; 63: 552-560

27. Grafe P, Mayer C, Takigawa T, Kamleiter M, Sanchez-Brandelik R. Confocal calcium imaging reveals an ionotropic $\mathrm{P} 2$ nucleotide receptor in the paranodal membrane of rat Schwann cells. J Physiol 1999; 515: 377-383.

28. Wang $X$, Arcuino G, Takano T, Lin J, Peng WG, Wan $P$ et al. $P 2 X 7$ receptor inhibition improves recovery after spinal cord injury. Nat Med 2004; 10: 821-827.

29. Coddou C, Yan Z, Obsil T, Huidobro-Toro JP, Stojilkovic SS. Activation and regulation of purinergic P2X receptor channels. Pharmacol Rev 2011; 63: 641-683.
30. Beis I, Newsholme EA. The contents of adenine nucleotides, phosphagens and some glycolytic intermediates in resting muscles from vertebrates and invertebrates. Biochem $J$ 1975; 152: 23-32

31. Easterbrook-Smith SB, Wallace JC, Keech DB. Pyruvate carboxylase: affinity labelling of the magnesium adenosine triphosphate binding site. Eur J Biochem 1976; 62: 125-130.

32. Craighead MW, Middlehurst KM, LeFeuvre R, Kimber I, Rothwell NJ. Oxidised adenosine 5'-triphosphate, a P2X(7) antagonist, is toxic to rat cerebellar granule neurones in vitro. Neurosci Lett 2001; 311: 77-80.

33. Schneider EM, Vorlaender $\mathrm{K}, \mathrm{Ma} X, \mathrm{Du} \mathrm{W}$, Weiss M. Role of ATP in trauma-associated cytokine release and apoptosis by P2X7 ion channel stimulation. Ann N Y Acad Sci 2006; 1090: 245-252.

34. Le Feuvre R, Brough D, Rothwell N. Extracellular ATP and P2X7 receptors in neurodegeneration. Eur J Pharmacol 2002; 447: 261-269.

35. Skaper SD, Debetto $P$, Giusti $P$. The $P 2 X 7$ purinergic receptor: from physiology to neurological disorders. FASEB J 2010; 24: 337-345.

36. Franke H, Gunther A, Grosche J, Schmidt R, Rossner S, Reinhardt R et al. P2X7 receptor expression after ischemia in the cerebral cortex of rats. J Neuropathol Exp Neurol 2004; 63: 686-699.

37. Narcisse L, Scemes E, Zhao Y, Lee SC, Brosnan CF. The cytokine IL-1beta transiently enhances P2X7 receptor expression and function in human astrocytes. Glia 2005; 49: 245-258.

38. John GR, Simpson JE, Woodroofe MN, Lee SC, Brosnan CF. Extracellular nucleotides differentially regulate interleukin-1beta signaling in primary human astrocytes: implications for inflammatory gene expression. J Neurosci 2001; 21: 4134-4142.

39. Panenka W, Jijon H, Herx LM, Armstrong JN, Feighan D, Wei T et al. P2X7-like receptor activation in astrocytes increases chemokine monocyte chemoattractant protein-1 expression via mitogen-activated protein kinase. J Neurosci 2001; 21: 7135-7142.

40. Peng W, Cotrina ML, Han X, Yu H, Bekar L, Blum L et al. Systemic administration of an antagonist of the ATP-sensitive receptor P2X7 improves recovery after spinal cord injury. Proc Natl Acad Sci USA 2009; 106: 12489-12493.

41. Brockes JP, Fields KL, Raff MC. Studies on cultured rat Schwann cells. I. Establishment of purified populations from cultures of peripheral nerve. Brain Res 1979; 165: 105-118.

42. Luo J, Bo X, Wu D, Yeh J, Richardson PM, Zhang Y. Promoting survival, migration, and integration of transplanted Schwann cells by over-expressing polysialic acid. Glia 2011; 59: 424-434.

43. Zhang $Y$, Zhang $X$, Yeh J, Richardson $P$, Bo X. Engineered expression of polysialic acid enhances Purkinje cell axonal regeneration in L1/GAP-43 double transgenic mice. Eur J Neurosci 2007; 25: 351-361.

44. Chessell IP, Hatcher JP, Bountra C, Michel AD, Hughes JP, Green P et al. Disruption of the P2X7 purinoceptor gene abolishes chronic inflammatory and neuropathic pain. Pain 2005; 114: 386-396.

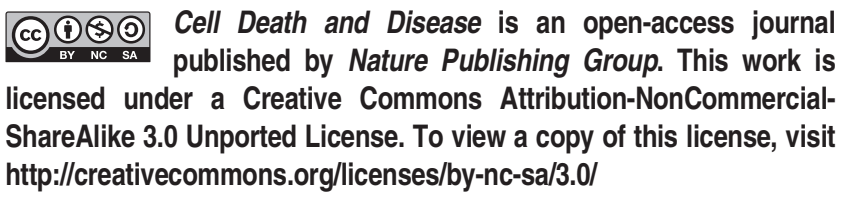

